\title{
Blockchain adoption in supply networks: a social capital perspective
}

\author{
Francesco Galati \\ Department of Engineering and Architecture, University of Parma, Parma, Italy
}

\begin{abstract}
Purpose - This study aims to contribute to the early but fervent debate on blockchain and supply networks by proposing a novel theoretical perspective on blockchain adoption grounded on social capital theory. In particular, it seeks to answer the following question: what is the role of social capital in shaping the decision to adopt blockchain in supply networks?

Design/methodology/approach - Multiple case-studies, based on interviews performed with managers of eight firms, were used.

Findings - The social capital theory emerged as an additional but necessary lens to investigate blockchain implementation in supply networks. The intuitions proposed highlighted the importance of managers' sensemaking for investigating technology adoption. Relational capital emerged as a necessary but not sufficient condition to adopt blockchain in supply networks. In addition, it is argued a relationship between competitive opportunities at the firm level and the idea to adopt the blockchain. The opportunity to act as "Tertius Gaudens" or as "Tertius lungens" information brokers in supply networks should severely affect firms' proneness toward the adoption of blockchain solutions.

Originality/value - This is one of the first studies in the literature investigating blockchain adoption in supply networks from a social capital perspective. It introduces new issues to the debate related to the role of blockchain in the supply chain by discussing the role of goal misalignment and competitive advantage, which emerged as crucial for shaping the decision to adopt blockchain in supply networks.
\end{abstract}

Keywords Blockchain, Supply network, Social capital theory, Structural hole, Broker, Social capital, Technology, Environmental uncertainty, Information flow, Theories, Strategic alliances

Paper type Research paper

\section{Introduction}

In a very broad sense, blockchain is "a distributed, consensusbased and (mostly) immutable ledger of transaction records" (Schmidt and Wagner, 2019, p. 1). It is considered a technological and philosophical innovation that will have disruptive effects on society as a whole (Hald and Kinra, 2019). This high expectation is raising the attention of academics, practitioners and regulators belonging to several industries (Davidson et al., 2018; Gaggioli, 2018; Cong and He, 2019; Allen et al., 2020). Such interest derives also from the global digitalization trend, labeled as Industry 4.0 in business contexts, which includes also $3 \mathrm{~d}$ printing, big data, robotics and machine learning (Galati and Bigliardi, 2019a; Birkel and Hartmann, 2020). Blockchain technology is a central element of the current digital transformation (Hald and Kinra, 2019).

There are two types of blockchain. The private ones require an invitation or permission to join, while public blockchains are open to anyone. Gupta (2017) suggested that private blockchains are ideal for the business context, as they allow enhanced operational efficiency and privacy. According to various authors (Yli-Huumo et al., 2016; Iansiti and Lakhani, 2017), the main features of blockchain are transparency and trust (information is viewable by all users), automation (actions

The current issue and full text archive of this journal is available on Emerald Insight at: https://www.emerald.com/insight/1359-8546.htm

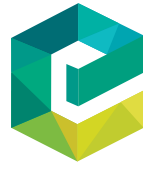

Supply Chain Management: An International Journal 27/7 (2022) 17-32

Emerald Publishing Limited [ISSN 1359-8546] [DOI 10.1108/SCM-12-2019-0448] can be programmed in advance), security (the distributed and encrypted nature of the system is hard to hack and single users cannot alter information) and disintermediation (the system eliminates the need for intermediaries).

Also in the supply chain environment, the debate around the role played by these innovative information and communication technologies (ICTs) is gaining momentum, as scholars and practitioners believe that this digitalization trend is already shaping the supply chain landscape (Birkel and Hartmann, 2019; Calatayud et al., 2019; Frederico et al., 2019; Garcia-Torres et al., 2019; Gligor et al., 2019; Liboni et al., 2019; Brinch et al., 2020; Nandi et al., 2020; Pasi et al., 2020; Seepma et al., 2020).

The improved information visibility could provide products' legitimacy, traceability and authenticity, thus becoming fundamental for industries - such as the food or the pharmaceutical ones - that would track the provenance of products (Gupta, 2017). In addition, data integrity, enabled by security, allows the storing of information and contracts that become immutable in the distributed ledger (Hald and Kinra, 2019). Moreover, supply chain efficiency can be also improved

(C) Francesco Galati. Published by Emerald Publishing Limited. This article is published under the Creative Commons Attribution (CC BY 4.0) licence. Anyone may reproduce, distribute, translate and create derivative works of this article (for both commercial and non-commercial purposes), subject to full attribution to the original publication and authors. The full terms of this licence may be seen at http://creativecommons.org/licences/by/4.0/legalcode

Received 16 December 2019

Revised 17 May 2020

7 January 2021

16 February 2021

Accepted 17 February 2021 
by the adoption of smart contracts, digital transaction protocols running on peers in a network that execute the terms of a contract (Kumar et al., 2019), which streamline supply chain processes. Finally, shared information can lead to remove delays in the physical movement of papers and the duplication of records, enhance inventory management and reduce waste, achieve more accurate demand forecasts and improve decision-making (Treiblmaier, 2018; Cole et al., 2019; Hald and Kinra, 2019; Queiroz and Wamba, 2019; Queiroz et al., 2019; Schmidt and Wagner, 2019; Wang et al., 2019; Rogerson and Parry, 2020).

As argued by Cole et al. (2019), blockchain will dramatically alter the current supply chain landscape and traditional supply chain models by changing the forces involved in market transactions. According to Schmidt and Wagner (2019), understanding the relationship between blockchain and the supply chain is crucial for academia and practice.

However, the academic debate dealing with blockchain and supply chain is at the beginning (Treiblmaier, 2018; Schmidt and Wagner, 2019; Wang et al., 2019). Despite a fast-growing number of papers on the topic, the research is still in its infancy (Queiroz et al., 2019; Wang et al., 2019). The topic is in a research phase characterized by several application-oriented papers (Hald and Kinra, 2019; Wang et al., 2019) and a few and preliminary attempts to develop a theoretical perspective of blockchain in the supply chain (Treiblmaier, 2018; Cole et al., 2019; Schmidt and Wagner, 2019; Wang et al., 2019).

Consequently, Treiblmaier (2018), Cole et al. (2019) and Hald and Kinra (2019) stressed the need for additional research on how blockchain technology relates to and challenges existing theory on supply chains, to further stimulate the academic debate. To date, scholars have mainly tried to explain the ex-post impact of blockchain on supply chains by adopting theories such as transaction cost economics, agency theory, resource-based view and network theory (Treiblmaier, 2018; Cole et al., 2019; Hald and Kinra, 2019; Kim and Shin, 2019; Queiroz and Wamba, 2019; Schmidt and Wagner, 2019).

First, blockchain is expected to have a noteworthy impact on supply chain transaction costs (Treiblmaier, 2018; Cole et al., 2019; Hald and Kinra, 2019; Queiroz et al., 2019; Schmidt and Wagner, 2019). Following transaction cost theory (Schmidt and Wagner, 2019), scholars claimed that the implementation of blockchain affects the efficiency of different types of governance mechanisms in terms of production and transaction costs. According to Schmidt and Wagner (2019) and Galati and Bigliardi (2019b), two assumptions ascribable to human behavior are crucial to transaction cost theory, namely, opportunism and bounded rationality. Blockchain is considered a structural solution able to lower opportunism and bounded rationality by reducing the costs for searching relevant information, negotiating with partners through smart contracts and controlling partners' actions, thereby enhancing decisionmaking (Treiblmaier, 2018; Schmidt and Wagner, 2019).

Agency theory (Jensen and Meckling, 1976) starts from the fact that organizations involved in a supply chain have different interests, thus seeing governance as a needed set of practices needed to guarantee the control and co-ordination of the chain (van Veen-Dirks and Verdaasdonk, 2009; Dolci et al., 2017). Treiblmaier (2018) stressed the role of asymmetric information flows between agents in the chain as the main problem highlighted by the agency theory, which imposes the creation of control systems and trust mechanisms. However, according to Treiblmaier (2018) and Cole et al. (2019), these systems and mechanisms are not anymore required with blockchain, given the transparent and accessible information flow that eliminates the demand for trust.

In addition, Treiblmaier (2018) stressed the importance of network theory for explaining the impact of blockchain in supply networks. It starts by considering that companies need to establish relationships to gain access to external resources and information, thus creating networks that are simultaneously stable and changing (Halldorsson et al., 2007; Dolci et al., 2017). In the view of Treiblmaier (2018) blockchain solutions can alter the concept of inter-organizational relationships by enhancing trusted information exchange between firms.

Finally, a different perspective, labeled as a resource-based view (Barney, 1991), was adopted. In the supply chain context, the perspective is concerned with the management of interorganizational resources to increase the competitive advantage of the partners (Dolci et al., 2017). This declination broadens the resource-based view by pointing out that relations are valuable and scarce resources at the supply chain level. Blockchain technology can lead to an increase of these types of resources through the possibility to incorporate blockchain into chain firms' portfolio of services and the improvement of agents' capabilities and firms' competencies (Treiblmaier, 2018; Kim and Shin, 2019).

In addition to the investigation of ex-post blockchain effects on supply chains, very few scholars have started to explore also the exante side of the problem, i.e. the antecedents of blockchain adoption in supply chains (Queiroz and Wamba, 2019; Cole et al., 2019; Kim and Shin, 2019; Wang et al., 2019). Cole et al. (2019) followed a traditional theoretical approach, grounded on the technology acceptance model and on the classical unified theory of acceptance and use of technology. A slightly different perspective was that adopted by Wang et al. (2019), who proposed sensemaking theory as useful to understand more in-depth managers' decisions to engage or not in collaborative agreements with other organizations and share information with them. According to this theory, through sensemaking managers try to project how blockchains may affect their business and the supply chain in which their firms operate. Wang et al. (2019) are the first to introduce a network perspective on the debate surrounding the adoption of blockchain in supply networks, stressing that "technological pre-adoption cannot be better understood without considering multiple interpretations of supply chain actors" (Wang et al., 2019, p. 233).

Considering social capital, Queiroz and Wamba (2019) investigated the role played by some of its components, focusing on structural issues and on trust but mixing the individual and the organizational level. In addition, an analysis of the study of Kim and Shin (2019), although its main focus on blockchain post-adoption effects, can lead to arguing that they considered structural features of social capital as antecedents of partnership efficiency and growth, which, in turn, can shape the decision to adopt blockchain. Kim and Shin (2019) also stressed the need to investigate social capital as an antecedent of partnership efficiency that may enhance coordination at the inter-organizational level.

Despite such interesting and promising research attempts, it is clear that these authors have begun to scratch the surface of the problem and that a satisfactory understanding of the 
phenomenon from a theoretical standpoint is far from being reached.

Against this background, the present study aims at contributing to this early but fervent debate by developing a novel theoretical perspective on the topic. It is positioned in the broad supply chain debate dealing with the role of social capital in supply networks (Bernardes, 2010; Cole et al., 2019; Kim and Shin, 2019). One of the research gaps arising from this debate refers to the understanding of the specific contributions of social capital in the context of supply network interactions. These interactions are crucial when investigating blockchain (Treiblmaier, 2018; Kim and Shin, 2019; Wang et al., 2019) but were previously investigated in very few studies that focused almost only on the structural dimension of social capital (Kim and Shin, 2019; Queiroz and Wamba, 2019). Moreover, while Kim and Shin (2019) highlighted the need to investigate social capital as an antecedent of partnership efficiency when considering blockchain, Cole et al. (2019) stated that social capital may be useless in understanding blockchain in supply chain settings.

Given these opposite positions, the need for additional research on how blockchain technology relates to and challenges existing supply chain theories and the paucity of studies dealing with social capital and blockchain adoption (despite its recognized helpfulness in supply chain contexts), we seek to answer the following question:

Q1. What is the role of social capital in shaping the decision to adopt blockchain in supply networks?

This study helps to answer this question by arguing that the cognitive and relational dimensions of social capital impact the decision to adopt blockchain solutions in supply networks. This is done by considering relational capital as a necessary but not sufficient condition to adopt blockchain and by proposing a relationship between competitive opportunities at the firm level and the idea to adopt blockchain. In fact, the opportunity to act as "Tertius Gaudens" or as "Tertius Iungens" information brokers in supply networks should severely affect firms' proneness toward the adoption of blockchain solutions.

This work challenges Cole et al.'s (2019) remarks by proposing that social capital theory is key for improving our understanding of the adoption of blockchain technologies in supply chains. Besides, this study posits that the inclusion of the social perspective in the academic debate could be considered one of the missing theoretical pieces that can help to improve the understanding of blockchain in supply chain contexts. Findings also suggest that social capital at the interorganizational level has a strategic value that can help to explain the decision to adopt a given technology in a supply network and help to understand more in-depth blockchain technologies. It is proposed that they should be intended not only as sociotechnical systems that alter the functioning of supply chain activities but also as solutions that can significantly alter the strategy and the competitive position of organizations involved in supply networks. Eventually, this study emphasizes the need to move beyond the traditional theoretical approaches grounded only on technology's functionalities and to consider additional perspectives rooted in social and competitive logics, highlighting the importance of social capital as an antecedent of partnership efficiency in supply networks and of technology adoption.

For the sake of clarity, the more general concept of "supply network" is preferred instead of the narrower "supply chain." According to Lamming et al. (2000), the incorporation of the term "network" embodies the attempt to extend the concept to more complex settings and include also strategic considerations.

\section{A novel perspective for understanding the adoption of blockchain in the supply chain}

2.1 Social capital theory in supply chain

Several scholars (Krause et al., 2007; Bernardes, 2010; Johnson et al., 2013; Mora-Monge et al., 2019) proposed social capital theory as fundamental to understand relationships in the supply chain. Social capital, according to Granovetter (1992) and Woolcock (1998), can be defined as a valuable asset that stems from access to resources (such as information and norms of reciprocity) made available through social relationships. For Burt (2001), social capital is the sum of actual or virtual resources that accrue to an organization by virtue of possessing a durable network of more or less institutionalized relationships of mutual acquaintance and recognition.

The concept is considered important for creating inimitable value-generating resources, intrinsic in a firm's network of relationships (Wu, 2008). Bernardes (2010) stressed that social capital or embeddedness is one of the central tenets of social network theory and affects economic transactions. $\mathrm{He}$ distinguished between personal relations (relational embeddedness) and the structure of the collective arrangement of such relations (structural embeddedness) and claimed that social capital has a remarkable effect on organizations' behavior and performance. A high level of social capital should improve supply network performance because it implies the generation of shared norms, rules and routines and the adoption of similar cognitive frameworks between partners (Bernardes, 2010).

For analytical purposes, Nahapiet and Ghoshal (1998) categorized social capital into three interrelated dimensions: structural, relational and cognitive.

\subsubsection{Structural capital}

Structural capital refers to network ties and configuration and is linked to the flow of information in a supply chain. Considering a focal firm, network ties refer to its aggregated ties with other firms that allow access to partners' information and other resources (Wu, 2008; Johnson et al., 2013). Network configuration denotes not only the density, hierarchy and connectivity of a social network but also how these features affect the level of connection and accessibility partners provide (Nahapiet and Ghoshal, 1998).

\subsubsection{Relational capital}

Relational capital was defined as the configuration and social structure of the network through which resources are accessed (Cousins et al., 2006), contending that it can be assessed by the degree of trust, interaction and mutual respect that exists between firms. Trust has effects also on the other dimensions (i.e. structural and cognitive). Trust impacts information visibility by building confidence in sharing valuable information 
and knowledge with the partners (Johnson et al., 2013), thus affecting collaborative behaviors (Zacharia et al., 2009).

\subsubsection{Cognitive capital}

Cognitive capital consists of the resources providing the parties with shared representations, interpretations and systems of meaning (Nahapiet and Ghoshal, 1998). It is embodied in a shared vision and is present when partners have similar perceptions of common goals (Nahapiet and Ghoshal, 1998). Inkpen and Tsang (2005) stressed that goals are shared when partners share a joint understanding and approach to the achievement of tasks and outcomes. If goals are shared in a supply chain, partners can be expected to have a shared understanding of improvements and how to accomplish it, which favors continued interactions between the partners and should result in a self-reinforcing process of participation in sensemaking (Johnson et al., 2013).

Similarly, Krause et al. (2007) claimed that shared goals and business vision are the primary dimensions of cognitive capital. They stressed that if goals and values are shared by buyers and their suppliers, continued interactions should result in an improvement in terms of cost, quality, delivery and flexibility. According to the perspective presented by Krause et al. (2007), in the present study cognitive capital is considered a shared representation of the business vision by all members of the supply network. In other words, this study considers cognitive capital as a situation of strategic goals alignment, in which the chain partners pursue the same objective in the long run by adopting a shared supply chain strategy.

\subsection{Blockchain adoption and social capital}

The present study infers that social capital theory is key for understanding the adoption of blockchain technologies in supply chains. It represents one of the first attempts to explain how social capital affects the adoption of blockchain solutions.

In the pre-adoption stage, the idea to adopt a blockchain solution stimulates the firms' evaluation process. During this process, firms hypothesize blockchain's potential effects and decide whether to adopt or not the solution. In the past, the technology acceptance model was used to explain why firms implement a given technology. However, this study posits that blockchain represents a completely different situation that has an impact on issues such as information visibility, which involves strategic considerations at both the organizational and inter-organizational levels that can alter the competitive position of firms.

We noticed that the literature ignored the relevance of two of the three dimensions of social capital, namely, the relational and the cognitive one, in debate dealing with the investigation of blockchain adoption in the supply chain. The focus, as stated above, was only on the structural capital, while the others were only skimmed or ignored. For this reason, this study focuses on the relational and cognitive dimensions of social capital.

\subsubsection{Relational capital}

Previously, it was stressed that relational capital is related to the degree of trust, interaction and mutual respect that exists between firms. Inter-organizational trust, in particular, can help to reduce uncertainty in supply chain decision-making and intensifies mutuality in goal settings (Ghosh and Fedorowicz, 2008).
Trust reflects the confidence of a given firm that the chain partners will not exploit its weaknesses (Ghosh and Fedorowicz, 2008), a concept that gains importance in supply chain transactions characterized by asymmetric information and uncertainty. Trust is based on evaluations made on the basis of the information referred to partners' actual characteristics and past behaviors. According to Bourdieu (1986, p. 27), trust depends also on symbolic capital, defined as:

[...] capital - in whatever form - insofar as it is represented, i.e. apprehended symbolically, in a relationship of knowledge or, more precisely, of misrecognition and recognition, presupposes the intervention of the habitus, as a socially constituted cognitive capacity.

In inter-organizational settings, symbolic capital refers to the prestige and recognition characterizing each organization, which, in turn, shape trust. Nevertheless, social capital may strengthen symbolic capital by functioning as a certification of social credentials and may also reinforce identity and recognition (Lin, 2002; Ihlen, 2005).

Information about other firms is difficult to be obtained. However, when firms collaborate, they can gain both explicit and implicit information about each other. Explicit information refers, for example, to technological readiness or financial stability, while implicit one refers to issues such as integrity or collaborative proneness, which are more difficult to obtain. Consequently, it is reasonable to suppose those past interactions that occurred between firms shape trust (Gulati, 1998).

Wu (2008) proposed that successful repeated transactions improve inter-organizational trust and mutual respect between firms. Transactions are defined as business interactions that occur in the long-run with the aims of combining complementary resources and cultivating shared representations of future developments (Polanyi, 1962; Quintas et al., 1997). They can be classified in past and future transactions. Future (expected) transactions depend on relational experience accumulated by firms in the past and shape inter-organizational trust by reducing the stimulus to behave opportunistically, as firms can have the fear of losing future business opportunities (Dyer, 1997; Williamson, 1999).

Some authors (Ghosh and Fedorowicz, 2008; Wu, 2008; Cole et al., 2019) made a further step by claiming that interorganizational trust affects the firms' propensity toward information sharing and visibility. This because interorganizational trust mitigates problems ascribable to information asymmetries that are intrinsic in inter-firm relationships by allowing a more open and honest sharing of information, which, in turn, alleviates the fear that partners will act speculatively (Wu, 2008). Although firms are often afraid to share their data and knowledge with others, in supply chain environments information visibility with trustworthy partners can be useful for coordination, integration, transparency and quality of products purposes (Treiblmaier, 2018; Cole et al., 2019; Wang et al., 2019).

However, a private blockchain forces information visibility among selected partners. Information shared with partners can range from inventory levels or product certification to financial and legal issues. Consequently, firms should carefully assess partners before adopting a blockchain solution. In so doing, they should rely also upon past actions to assume future trustworthy behavior, to assess more rationally the blockchain implementation. 


\subsubsection{Structural issues and cognitive capital}

Supply chains may range from simple to complex structures involving a network of firms performing different tasks (Pathak et al., 2014). Both in simple and in complex network structures, firms collectively attempt to meet demand through individual firm-level activities while responding to variations in the environment and in activities performed by other firms in the supply chain (Choi et al., 2001). According to this perspective, supply chain firms can cooperate, compete or co-opete (Wu and Choi, 2005; Pathak et al., 2014). Before deciding to engage in collaborative agreements and adopt a blockchain solution, firms should assess the pros and cons of this choice through an often heuristic process based on their intuitions, feelings and presumed frames. The idea is that firms are strongly influenced by the evaluation of their actual and potential competitive/ cooperative position with reference to the opportunity to act or not as information brokers, thus exploiting structural holes in the supply network.

To understand the structural hole concept, it is possible to recall an example involving a triad of organizations belonging to a supply network. In this case, a structural hole occurs between two organizations when they are linked to the same organization but are not linked to each other (Carnovale et al., 2016). The concept is linked to the resource dependence theory (Pfeffer and Salancik, 1978), which treats firms as entities embedded in a network of exchange relationships within an uncertain environment and dependent on other firms' resources for survival. Within supply networks, firms' power resides in others' dependence on their resources (Schmidt and Wagner, 2019). Resources generate dependence when they are important and control over them is exerted by a few organizations (Pfeffer and Salancik, 1978). Information and knowledge are considered crucial resources in supply networks, as they decrease environmental and behavioral uncertainty (Carnovale et al., 2016). For this reason, firms are strongly dependent on organizations possessing them. Consequently, it is possible to consider structural holes as missing connections that hinder information flow between chain firms (Burt, 2007; Swierczek, 2020).

The competitive implications deriving from the existence of this structural feature in supply networks are grounded on the brokerage activity that the organization connecting the others can fulfill. The brokerage was defined as the process by which organizations acting as intermediaries can smooth connections between other organizations lacking access to or trust in one another (Carnovale et al., 2016). Firms acting as brokers in supply networks may take advantage of structural holes by having access to and manage a diverse set of partners, resources and non-redundant information and "translate it across groups" (Carnovale et al., 2016). Furthermore, Burt (2009) suggests that brokers gain benefits also from the control that allows the broker to leverage the disengaged organizations against one another. Accordingly, Pathak et al. (2014) and Schmidt and Wagner (2019) suggested that the competitive power of a broker resides in the opportunity to block a potential connection or to link two otherwise disengaged organizations, a situation that can alter the existing relational dynamics in the supply network. These two distinct scenarios (Pathak et al., 2014) were labeled as "Tertius Gaudens" and "Tertius Iungens".
The "Tertius Gaudens" scenario refers to the opportunity that the organization connecting the other two has to leverage on the disunion of the others (Baker and Obstfeld, 1999). By so doing, the broker intermediates the exchange of resources and information between the brokered organizations by acting as the only route through which resources and information flow across the structural hole (Quintane and Carnabuci, 2016). Under this perspective, the broker firm can benefit by not intervening in the disconnection between the other organizations or by playing off disconnected organizations against one another (Obstfeld et al., 2014).

The "Tertius Iungens" scenario refers to a situation in which the broker organization finds it beneficial to facilitate the connection - and thus, at least, the flow of information - across the structural hole by allowing a connection between the brokered organizations (Obstfeld et al., 2014). This opportunity is related to the union and combination of the disconnected organizations, in which the broker considers advantageous the potential synergistic effects deriving from directly connecting the brokered organizations (Pathak et al., 2014). This decision is not easy for the broker organization, as it implies giving up power and control, act as "non-partisan" and embrace self-coordination in the supply network triad to create group unity (Obstfeld, 2005).

Depending on the context and timing in which such brokerage alternates are adopted, previous research demonstrates that these strategies can help to explain organizations' behaviors in supply networks and be both effective (Long Lingo and O'Mahony, 2010; Obstfeld et al., 2014).

Blockchain forces network closure, a situation in which every partner is connected such that no one can escape the notice of others, characterized by a high level of information visibility. This was often recognized, in supply chain environments, as a desirable situation for information transparency, quality of products, coordination and integration (Pathak et al., 2014; Treiblmaier, 2018; Cole et al., 2019; Wang et al., 2019). Some of these authors stressed that, through blockchain, supply chain firms can comply with differentiated demands from consumers, quickly recall products from markets when incidents occur, optimize business processes through integrated information and cope with the quality of products by tracing products' chain.

However, these considerations were always made at the supply chain level, while the single firm perspective was only skimmed (Wang et al., 2019). Nevertheless, the implementation of blockchain solutions relies upon interorganizational agreements that must be accepted by all partners. Thus, it should be of interest also to understand why each individual-firm in a supply network can find counterproductive the adoption of blockchain. For example, it could be possible that firms are interested in preserving some sort of information asymmetry to keep competitive advantages.

This study posits that the crux of the problem could be the cognitive capital concept, inferring a relationship between structural and cognitive issues. In the above, it was stressed that cognitive capital is embodied in a shared vision and is present when partners have similar perceptions of common goals and how they should interact and that goals are shared when partners share a joint understanding and approach to the 
achievement of tasks and outcomes. The decision to adopt a blockchain solution involves different firms, each with its own goals, ideas and constraints.

Therefore, if at least one organization acting as a broker in a supply network that is assessing the possibility to adopt a blockchain solution does not judge as competitively convenient this scenario (Tertius Gaudens scenario), the degree of cognitive capital at the supply network level should diminish, as well as the probability that the supply network would adopt the blockchain. Conversely, if organizations acting as brokers in a supply network that are assessing the possibility to adopt a blockchain solution judge as competitively convenient this scenario (Tertius Iungens), the degree of cognitive capital at the supply network level should increase, as well as the probability that the supply network would adopt the blockchain.

\section{Methodology}

\subsection{Research design}

To answer our research question, we used the multiple casestudies methods. It is particularly suited to investigate a real-life, complex and non-routine phenomenon in-depth - such as the role of social capital in shaping the decision to adopt blockchain in supply networks - and is appropriate for theory development (Yin, 2009). Further, an abductive approach (Timmermans and Tavory, 2012) was adopted, using constructs developed by combining the extant literature on social capital theory, supply chain theories on brokerage activities and blockchain. Abductive reasoning smooths the discovery of knowledge, which begins with preliminary theoretical knowledge before collecting empirical data, continues with theory matching and suggests propositions based on observations and ends with theory development or extension.

We focused our analysis on the strategic behavior and the social capital of sets of firms operating in a supply network with reference to the decision to adopt blockchain. To allow us to draw conclusions on these issues, we decided to use extreme cases due to their potential to offer potent depictions of some of the target phenomenon's characteristics (Galati and Bigliardi, 2019b; Scholten et al., 2019). The selection of cases for this study was, therefore, based on theoretical replication (Yin, 2009). The theoretical sampling plan considered groups of a firm belonging to a specific supply network involved in the decision to adopt a blockchain and, following Yin, (2009), polar types were selected (i.e. decision to adopt or not the blockchain). This sampling plan was designed to obtain a more in-depth understanding of the phenomenon by replicating similar conditions (such as the industry in which firms operates, size of firms, their role in the supply chain) but altering only one experimental condition (i.e. decision to adopt or not the blockchain) to verify the possibility to predicts contrasting results but for predictable reasons.

With this in mind, we conducted two case studies in the food industry (Figure 1). This industry was chosen due to its economic importance for many countries and for the potential relevance of blockchain in food supply chains (Cole et al., 2019). The structure of the parts of the supply networks investigated is the same for the two cases. Each case is composed of two producers of fruits and vegetables, one food trader operating in different supply chains and an international food company. In brief, producers sell their food products to the trader, who store and then sell products to the food company, who process these products. Firms are named here as P1, P2, P3, P4, FT1, FT2, IFC1 and IFC2 and specific details relating to their locations and the names of managers and firms are disguised to preserve anonymity.

\subsection{Data collection}

The core data of this study are made up of semi-structured interviews across the eight firms involved. For each firm, we selected those individuals involved in the decision to implement the blockchain solution (Table 1). The interviewees selected were expected to have an understanding of supply chain flows (i.e. material, service, information and money) before the implementation of the blockchain. Each interview was conducted at the organizational level because of the aim of the study, to understand the role of social capital in shaping the decision to adopt blockchain in supply networks. To judge the level of social capital in each case performed, we considered it important to understand the perspective of each organization involved in the chain and then made a judgment at the network level. We sought multiple viewpoints to enable a deep and informed understanding of specific situations and reactions in relation to the topic investigated.

We arranged semi-structured interviews, one for each firm, lasting five months. Almost all interviews were performed using Skype face-to-face calls. Only the interview conducted on IFC2 was performed personally. For each firm, the interview was recorded and transcribed by the researchers. We performed several follow-up phone calls with interviewees to add missing details and to confirm the validity of our transcribed data and interpretation.

The literature review inspired the development of the interview protocol. Each interview followed a standard protocol (to allow data comparison) organized under broadly defined themes and through open-ended questions. It includes a general question to investigate the background and position of the interviewee, the competitive position of the firm and the perceived strategic importance of blockchain adoption in the supply network with reference to each firm's relationships, advantages and competitive position. Interviewees were asked to recall specific motives and related behaviors/decisions with reference to blockchain adoption. Interviewees were also asked to judge social capital issues (such as trust in chain partners, the flow of information, frequency of collaborations, convergent or divergent strategic perspectives) at the time of blockchain evaluation. Following the recommended approach for triangulating data from multiple sources, we also collected data not only from interviews but also from additional documents, archival data, mass media articles, social media comments and websites, for improving data reliability.

\subsection{Data analysis}

We followed multiple case-studies guidelines for theory development as we collected and analyzed the data, thus continuously contrasting initial theory and data gathered throughout our interviews (Yin, 2009). The analysis focused on examining the antecedents of the decision-making process in terms of social capital considering all different perspectives. Each interview was first transcribed and then codified according to the literature review. Such structure helps to summarize our findings. 
Figure 1 The two case studies performed (arrows show the flows of food products)

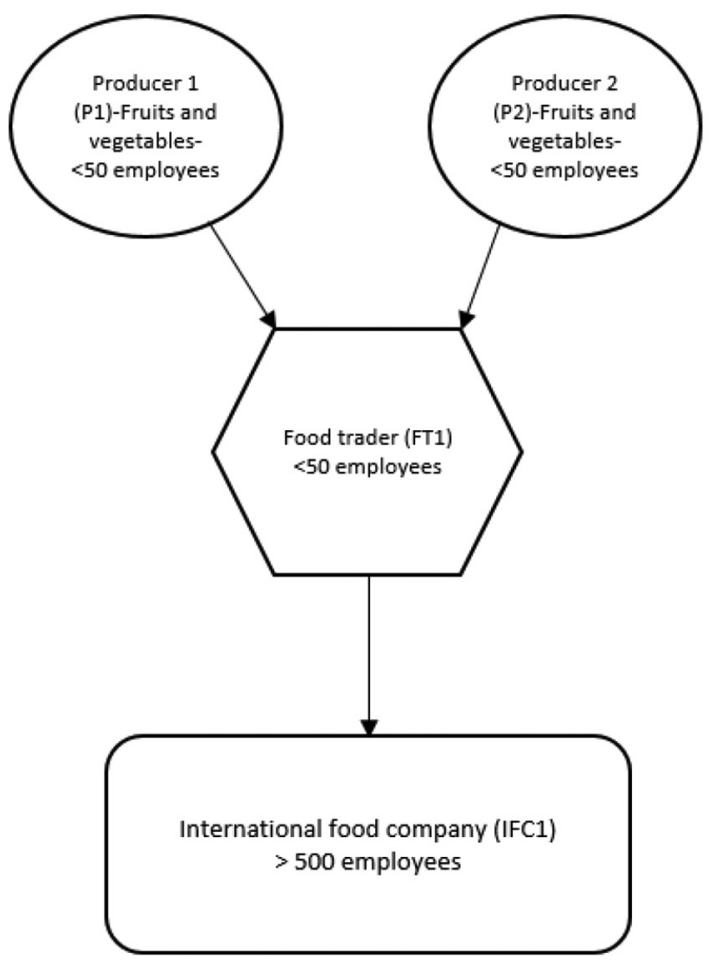

CASE 1

Have adopted a blockchain solution

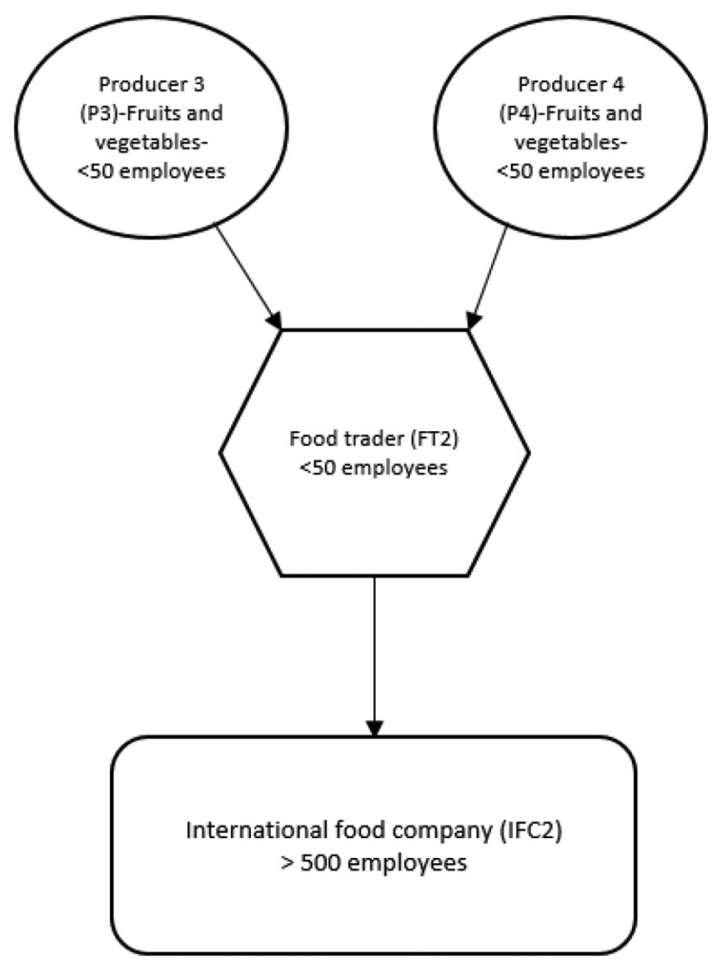

CASE 2

Have not adopted a blockchain solution

Table 1 People interviewed for each firm and duration of the interview

\begin{tabular}{|c|c|c|c|}
\hline Case & Firm & Position of the interviewees & Duration of the main interview \\
\hline Case 1 & P1 & Owner & $70 \mathrm{~min}$ \\
\hline \multirow[t]{7}{*}{ Have adopted a blockchain solution } & & IT manager & \\
\hline & P2 & Owner & $100 \mathrm{~min}$ \\
\hline & & Sales manager & \\
\hline & FT1 & Owner & $90 \mathrm{~min}$ \\
\hline & & Sales manager & \\
\hline & IFC1 & Purchasing manager & $140 \mathrm{~min}$ \\
\hline & & $\begin{array}{l}\text { Supply chain manager } \\
\text { IT manager }\end{array}$ & \\
\hline Case 2 & P3 & Sales manager & $60 \mathrm{~min}$ \\
\hline \multirow{10}{*}{ Have not adopted a blockchain solution } & & IT manager & \\
\hline & P4 & Owner & $50 \mathrm{~min}$ \\
\hline & & IT manager & \\
\hline & $\mathrm{FT} 2$ & Purchasing manager & $100 \min$ \\
\hline & & Sales manager & \\
\hline & IFC2 & Purchasing manager & $220 \min$ \\
\hline & & Logistics manager & \\
\hline & & Supply chain manager & \\
\hline & & IT global manager & \\
\hline & & Marketing manager & \\
\hline
\end{tabular}

Data analysis began with respect to both the firms' perceived advantages and challenges related to blockchain, as we were interested in detecting their attitude toward the specific technological solution and their understanding of the strategic relevance of blockchain for their business. Then, we codified the other issues referred to as social capital. More in detail, the level of relational capital was considered high/low by judging the frequency of contacts within supply chain partners, the 
nature of personal links, the level of trust and commitment devoted to the partnership. Cognitive capital was investigated and then codified in our study by assessing the presence or not of a shared vision along the supply chain. This means to understand whether supply chain players have a common understanding of consumers' needs, market trends and partners' action and priorities and of strategic issues. In other words, if the business vision was the same in all firms belonging to each case study, the level of cognitive capital within the supply chain was considered high. This includes the case in which broker firms find it beneficial to facilitate the information flow across the structural hole by allowing a link between the brokered organizations (Tertius Iungens scenario). Conversely, if we noticed a different business perspective by one or more firms belonging to the chain, the level of cognitive capital was considered low. This includes the case in which broker firms find it beneficial to limit the information flow across the structural hole (Tertius Gaudens scenario).

We then group them according to the structure that emerged from the literature, analyzed themes and sought commonalities and interrelationships (Galati et al., 2019), which were identified through the continuous reading and re-reading of interviews. The phases of the empirical investigation were alternated with theoretical reconsideration. For each firm, we performed several follow-up phone calls with interviewees to confirm the validity of our interpretation. The within-case was performed at the (part of the) supply network level by combining the different organizational perspectives. Finally, through the cross-case phase, we compared the results collected through the within-case analysis to derive similarities, differences and new issues. The reiteration of this process leads to identify the suggested set of theoretical propositions.

\subsection{Methodological rigor}

To assess the trustworthiness of the methodology underlying this study, our data and analyzes were designed to meet the quality criteria of fit, understanding, generality and control (Strauss and Corbin, 1998). As for the fit, data collection and analysis were based on an initial idea stimulated by the literature and participants were strongly integrated into the study (they also participate in the development of propositions). As for the understanding, transcription and results were sent back to participants, thus they understood and approved the findings. In terms of generality, interviews' length and openness allow capturing diverse aspects of the phenomenon because of the different perspectives of firms included in the study. Finally, control was ensured by involving interviewees who can exert a decisive influence on the decision to adopt blockchain at both the organizational and the supply network levels.

\section{Findings}

\subsection{Preliminary information}

The first part of the study was aimed at understanding the objective motives that drive the decision to adopt or not blockchain solutions. Findings from both within and cross-case analysis showed that the objective operational advantages provided by blockchain solutions were recognized by all interviewees. All of them were sufficiently informed about blockchain's features also with reference to their specific business and their role in the supply chain. We noticed that the proposal to adopt the blockchain in both cases started from the international food companies involved in the supply networks. They were ready to invest in this technology for specific reasons but this positive attitude toward blockchain emerged from all firms.

The most cited benefits were products' legitimacy, traceability and authenticity, as well as the achievement of more accurate coordination and flexibility. For example, as stated by the supply chain manager of IFC2:

[...] firms operating in industries in which products' authenticity plays a crucial role for firms in the chain and for consumers are increasingly interested in such digital technologies, who can assist and improve our work.

The owner of P2 stressed that "Authenticity and traceability allowed by blockchain's features help food producers that pay attention to foods' superior quality and ensure process monitoring, which is critical in our industry." Moreover, as argued by the IT manager of $\mathrm{P} 4$ :

Our firm is very small and is at the beginning of the network. Blockchain solutions improve demand forecasts and can help us in improving our firm's identity and sense of belonging to a wider community.

As for the challenges, various issues appeared. Among the others, the lack of a standardized solution and of regulation, as well as the required implementation and integration costs resulted to be the most evident. However, we noticed that these challenges were perceived the most by large firms (IFC1 and IFC2). This was linked to the required IT investments and with the difficulty of integrating a specific blockchain solution with firms' ERP systems:

Blockchain development is still at an early stage, in which food firms are exploring some business implementation cases and are not ready to fully exploit blockchain potential. In addition, there is still a lack of regulation, IT competencies are not largely diffused and consumers do not recognize the value that these technologies can provide to their day-to-day purchasing activities. Therefore, I'm not surprised about the low level of blockchain adoption, stressed the IT manager of IFC1.

However, also the sales managers of FT1 and FT2 raised similar doubts. More in detail, that of FT1 claimed:

The lack of regulation and standard solutions make difficult for traders to choose a specific blockchain solution, as we can face the risk of being involved in different supply chain adopting different blockchain solutions, thus increasing the technological complexity of our activities.

\subsection{Relational capital and cognitive capital}

The second part of our investigation identifies the different social capital mechanisms that shape the decision to adopt or not blockchain in supply networks. As for the investigation of relational embeddedness, the within-case analysis depicted a clear relationship between relational elements - such as interorganizational trust, obligation and partners' symbolic capital and firms' proneness to adopt blockchain. Trust was considered crucial and necessary by all firms. The purchasing manager of IFC1 stressed:

We cannot implement a blockchain, which requires an intimate interaction, with untrustworthy partners. The supply network you are analyzing is made of some of our historical partners, we totally trust them.

He was echoed by the logistics manager of IFC2 "It's impossible to adopt blockchain in a supply network in which trust and respect are not diffused within actors. Our blockchain 
adoption attempt was developed only with trustworthy suppliers." The purchasing manager of FT2 claimed that:

We trust the firms considered in your study, we have a long history of success together [...] we also feel obliged to them, as they continuously help us in improving our performance [...] it's an honor for us to work with IFC2, given their recognized prestige at an international level [...] if considering only our relational closeness, we would accept blockchain implementation.

Underlying new issues such as obligation and symbolic capital. These issues emerged also from the words of P1:

We are prone to do anything FT1 and IFC1 ask to improve the technological readiness of chain [...] we consider them our business family, a distinguished business family recognized globally.

From the within- and the cross-case analyzes, it emerged that blockchain adoption was evaluated (and implemented by firms included in Case 1 by involving only trustworthy and respected partners. Partners in both cases appeared to be very well connected, recognized and trusted. Relational capital seems to be a necessary condition to adopt blockchain in a supply network, according to the interviewees. However, we are aware that only firms belonging to the supply network depicted in Case 1 have decided to implement the blockchain solution, thus relational capital alone could not be considered sufficient to explain why supply networks decide to adopt this technological way.

Our investigation goes further through the analysis of the cognitive capital dimension, which includes considerations at the strategic and competitive level. First, the within-case analysis was performed. The analysis started with reference to Case 1. Managers stressed the need to coordinate their activity to obtain benefits at the supply chain level. The IT manager of P1 stated, "Blockchain gives us the opportunity to align information flows within the chain, which could be very useful for us in the long run." The same perspective emerged from the IT manager of IFC1:

Blockchain solutions can help to create a shared vision at the network level [...] we feel somehow incentivized to define a unified strategy at the chain level [...] we hope that the implementation of blockchain would improve the chain resilience through meetings devoted to the development of tactics able to strengthen our competitive position.

Interesting findings resulted from the position of the managers belonging to the trader firm (FT1), which could be fundamental (according to the literature review on the role of brokers) for cognitive capital reasons.

The words of the sales manager highlighted something that previous literature on blockchain in the supply chain does not yet consider:

[...] coordinating activities at the network level is of primary importance for our success, also due to the reduction of the bullwhip effect that provides benefits to the entire chain [...] our power resides in the ability to match and negotiate information about products and prices [...] blockchain could reduce our negotiating power, but we believe that allowing the implementation of blockchain in our work can be viewed as a signal of trust by our customers [...] our customers can believe that we have nothing to hide [...] we are confident that these technological advancements would improve our business.

It resulted that FT1 act as tertius iungens, as they prefer to establish a connection between its suppliers and customer through blockchain instead of preserving its advantage deriving from acting as an information broker. Considering the level of cognitive capital at the supply network level, Case 1 represents a situation of high cognitive capital level, in addition to the high relational embeddedness. All firms are strongly linked together, not only in terms of trust and respect but also when considering strategic fit at the inter-organizational level. All firms stressed the need to improve coordination, even at the expense of their own negotiating power (such as the case of FT1). This context seems ideal for the adoption of a technological solution such as blockchain, characterized among the others by the presence of immutable, traceable and shared data, which allows network closure.

Case 2 highlighted different considerations. Also, in this case, almost all the interviewees considered important coordination activities. This was stressed by both producers, P3 and P4 and IFC2. The supply chain manager of IFC2 synthesize their thoughts:

We cannot act in isolation [...] we face global competition, thus coordination with supply chain actors is essential to respond quickly to the evolving customers' needs and preferences [...] the emergence of the new technologies give us unprecedented opportunities to coordinate our action [...] we can act as a single entity that provides benefits to all the partners involved in the game.

However, not all firms share a similar vision. FT2's managers, although recognizing the importance of coordination at the chain level, considered less desirable the transparent and distributed sharing of data with its partners:

Our activity is too much related to the effective management of data, which can be considered our main resource [...] our profits are strongly related to our negotiating decisions and derives from our competitive power [...] we are intermediaries, so our brokerage power is vital for us [...] after the exploration of blockchain potential and drawbacks, we believe that is impossible to accept this kind of technology [...] this was not an easy decision to take, we are strongly connected with our partners [...] the mismatch between the coordination of information deriving from our suppliers and customers is our strength, we need to preserve it and limit others' control stated the purchasing manager of FT2.

In this case, a focus on the strategic perspective of FT2 highlighted a tertius gaudens scenario, in which the broker firm acts to preserve its information broker position. This player in the supply chain did not accept blockchain implementation, thus impeding its adoption in the chain. This case represents a low level of cognitive capital at the supply network level, given the partners' goal misalignment:

After several months of experiments and meeting, our attempt to implement blockchain in our supply chain was judged as not convenient by FT2, so we decided to abandon this path [...] maybe FT2's managers were right and although we had different views, we believe that our partnership would not be affected [...] maybe we would consider other chains in which blockchain could be implemented stressed the marketing manager of IFC2.

This confirmed that the level of relational capital was high in the chain but also that the low level of cognitive capital due to the different perspective of FT2 has led to the impossibility for the chain partners to adopt blockchain.

Cross-case analysis highlights two different behaviors of the parts of the supply networks investigated (Figure 2).

While it emerged that the level of relational capital was high in both cases, which was considered a sine qua non for the implementation of blockchain, the analysis of the cognitive dimension of social capital brings to light crucial issues. The actor that plays a critical role in the decision-making process at the supply network level is the information broker, which in our cases is represented by the food trader. His logic is key for the decision to implement or not blockchain in the network.

A comparison of cases suggests that brokers acting as tertius iungens increase the level of cognitive capital at the 
Figure 2 Summary of case studies

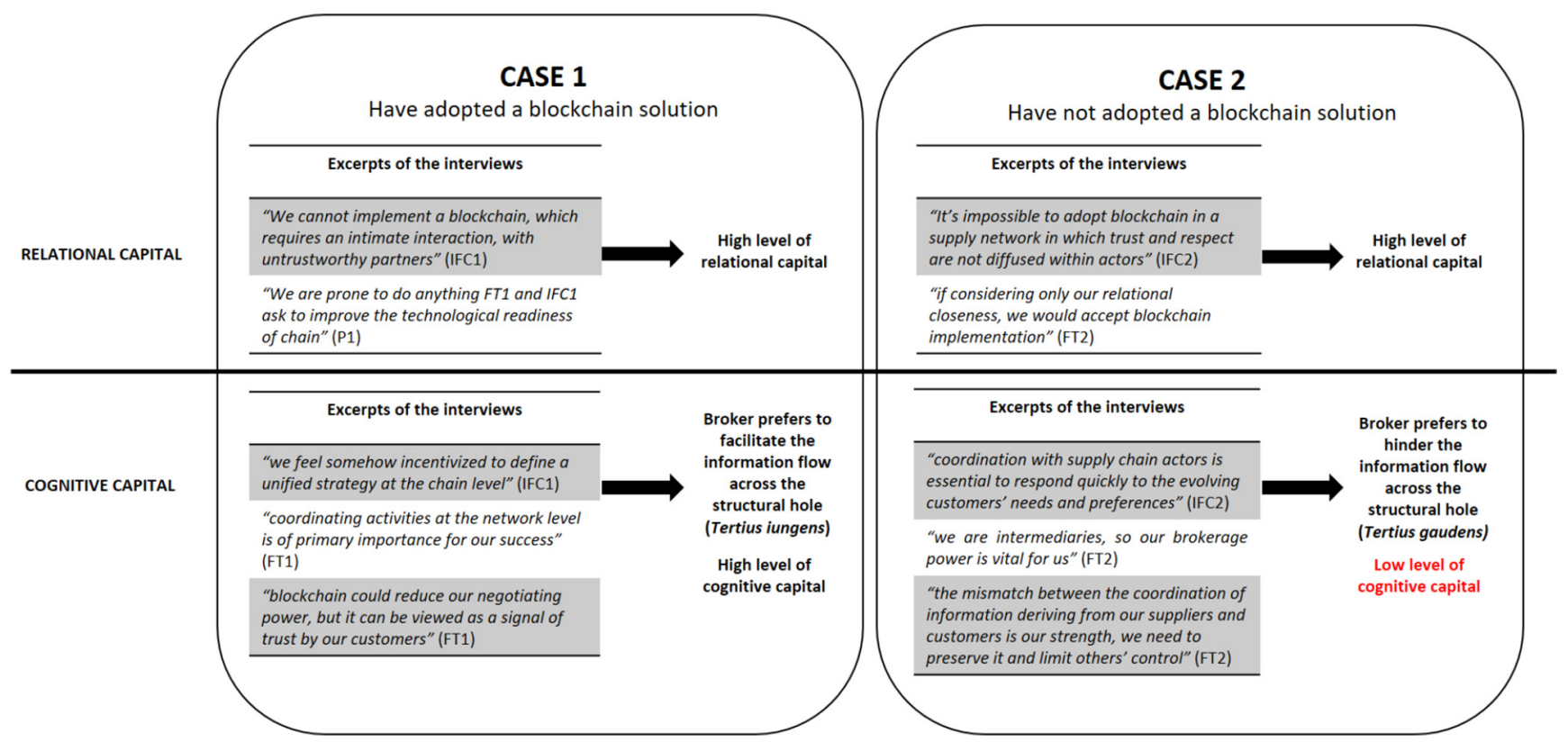

inter-organizational level, while brokers acting as tertius gaudens decrease such level. Given the similarity of the cases selected and analyzed, as well as the analogous high level of relational capital detected, it can be argued that the different outputs in terms of adoption of blockchain are due to differences in brokers' strategic cognition. While Case 1 involves FT1, which judged it convenient to facilitate information flows within the network by limiting its negotiation power, Case 2 includes FT2 that acts oppositely (i.e. hindering transparent information sharing across the chain). Given the similar high level of cognitive capital of all firms included in both cases when excluding brokers, we can assert that brokers make the difference with reference to the decision to adopt or not blockchain in a supply network.

\section{Discussion}

\subsection{Theoretical implications}

This work is positioned in the broad supply chain debate dealing with the role of social capital in supply network interactions (Bernardes, 2010; Treiblmaier, 2018; Cole et al., 2019; Kim and Shin, 2019; Wang et al., 2019). These interactions are crucial when investigating blockchain (Treiblmaier, 2018; Kim and Shin, 2019; Wang et al., 2019) but were previously considered in very few studies that focused almost only on the structural dimension of social capital (Kim and Shin, 2019; Queiroz and Wamba, 2019). It contributes to addressing the need to develop further theoretical advancements, raised by many scholars (Treiblmaier, 2018; Cole et al., 2019; Hald and Kinra, 2019; Schmidt and Wagner, 2019), by proposing a novel perspective grounded on social capital theory. This study posits that the inclusion of the social capital perspective in the academic debate could be considered one of the missing theoretical pieces that can help to improve the understanding of blockchain in supply chain contexts. It is suggested that the common institutional theory and technology acceptance model cannot be the only theoretical perspectives used to explain the adoption of a blockchain solution in supply chains because also the relational and cognitive dimensions of social capital shape this decision.

More in detail, it is first claimed that a high degree of relational capital in a supply network should increase firms' predisposition toward the adoption of blockchain solutions, while a low degree of relational capital should hinder the implementation of this technology. Following this line of reasoning, firms should be more prone to share information and collaborate with trustworthy, competent and respected partners. In other words, they should be more inclined to implement a blockchain solution with those with whom they have developed a satisfactory level of relational capital. What emerged from Case 2, however, signals that relational capital alone is not able to explain why supply networks decide to adopt or not blockchain. In fact, although a high level of relational capital, the network has not implemented blockchain. Therefore, by combining the theoretical arguments derived from the literature review and the findings emerged from case studies, we can suggest that:

P1a. A high degree of relational capital in a supply network improves chain firms' proneness to adopt blockchain solutions.

P1b. A high degree of relational capital in a supply network is a necessary but not sufficient condition to adopt blockchain solutions.

In addition, it is emphasized the decisive role of cognitive capital for the adoption of blockchain solutions in supply networks. This is done by proposing a relationship between competitive opportunities at the firm level and the idea to adopt the blockchain. The opportunity to act as "Tertius Gaudens" or as "Tertius Iungens" information brokers in supply networks 
should severely affect firms' proneness toward the adoption of blockchain solutions.

This study posits that if at least one organization acting as a broker in a supply network that is assessing the possibility to adopt a blockchain solution does not judge as competitively convenient this scenario, the degree of cognitive capital at the supply network level will diminish, as well as the probability that the supply network will adopt the blockchain. The focus is on brokers as they represent important nodes in the network according to the resource dependence theory (e.g. they possess significant information about other nodes). In this situation, which was labeled as "Tertius Gaudens," the degree of cognitive capital at the supply network level should diminish because not all partners in the supply network share common goals. It is proposed that the organization acting as a broker would be less inclined to accept the implementation of a technological solution, the blockchain, that would close a structural hole that the broker organization is exploiting. Therefore, it is argued that:

P2a. Firms that prefer to act as "Tertius Gaudens" information brokers in supply networks are less prone to adopt blockchain solutions.

P2b. Firms that prefer to act as "Tertius Gaudens" information brokers in supply networks will diminish the degree of cognitive capital at the supply network level.

P2c. Supply networks involving information brokers that prefer to act as "Tertius Gaudens" are less prone to adopt blockchain solutions.

Conversely, if organizations acting as brokers in a supply network that are assessing the possibility to adopt a blockchain solution judge as competitively convenient in this scenario, the degree of cognitive capital at the supply network level should increase, as well as the probability that the supply network will adopt the blockchain. In this situation, which was labeled as "Tertius Iungens," the degree of cognitive capital at the supply network level should increase because the brokers will sponsor the connection between unconnected partners in the supply network (to increase their own competitive positions). Moreover, there is at least an additional organization in the supply network (i.e. that acting as a broker) that would not pursue its own interest alone but with chain partners, which results in lower opportunism at the supply network level. In this case, brokers can consider the possibility that customers may prefer to buy products from firms that make available more detailed information about the products' supply chain. By so doing, brokers adopting blockchain before the others can consider it a strategic decision that would provide them a competitive advantage, at least in the short-run. Consequently, it would be probable that higher levels of shared visions and goal alignment can be achieved. Therefore, it is argued that:

P2d. Firms that prefer to act as "Tertius Iungens" information brokers in supply networks are more prone to adopt blockchain solutions.

P2e. Firms that prefer to act as "Tertius Iungens" information brokers in supply networks will increase the degree of cognitive capital at the supply network level.

P2f. Supply networks involving information brokers that prefer to act as "Tertius Iungens" are more prone to adopt blockchain solutions.

Among these two different scenarios (Tertius Gaudens and Tertius Iungens), this study does not suggest which one is better or preferable for firms operating in supply networks. They can be considered effective in the appropriate context. Our findings try also to relate each of them with a given level of cognitive capital at the supply network level, which, in turn, should affect the decision to adopt blockchain at the inter-organizational level. Figure 3 resumes what has been proposed, thus depicting the entire process.

This study can be considered complementary to those of Kim and Shin (2019) and Queiroz and Wamba (2019). The intuitions proposed with reference to the pre-adoption stage support also those provided by Wang et al. (2019), which highlighted the importance of pre-adoption sensemaking at the organizational level for investigating technology adoption. Blockchain pre-adoption cannot be completely understood without considering the different urges and perspectives of each organization in the supply network. Furthermore, this study introduces new issues to the debate related to the role of blockchain in the supply chain by discussing goal misalignment and competitive advantage. They can exert a decisive influence on the decision to adopt or not blockchain in networks of firms.

In addition, our findings help to shed light on the future research avenue introduced by Kim and Shin (2019), who highlighted the need to investigate social capital as an antecedent of partnership efficiency that may enhance coordination at the inter-organizational level. Our study suggests that social capital is a necessary pre-requisite for enhancing coordination at the supply network level. This because the decision to implement a technology (blockchain) that is widely recognized for improving partnership efficiency and coordination in supply chains can be neglected by a low level of relational or cognitive capital.

Findings also suggest that social capital at the interorganizational level has a strategic value that can help to explain the decision to adopt a given technology in a supply network. It can help to understand more in-depth not only the adoption of blockchain but also other technologies having similar characteristics such as information sharing and transparency, who can alter the competitive power of firms in supply networks.

\subsection{Managerial implications}

Although many managers are aware of the potential and challenges of blockchain in supply networks, they may be less familiar with the role of relational and cognitive capital in shaping the decision to adopt or not blockchain at the supply network level and more in general to partnership efficiency. This study provides valuable insights to address this practitioner's requirement.

We show how the decision to adopt blockchain is related to the convergence (or divergence) of competitive and strategic goals of firms involved in the network, as well as to the level of 
Figure 3 A relational and cognitive capital perspective on the blockchain adoption process in supply networks

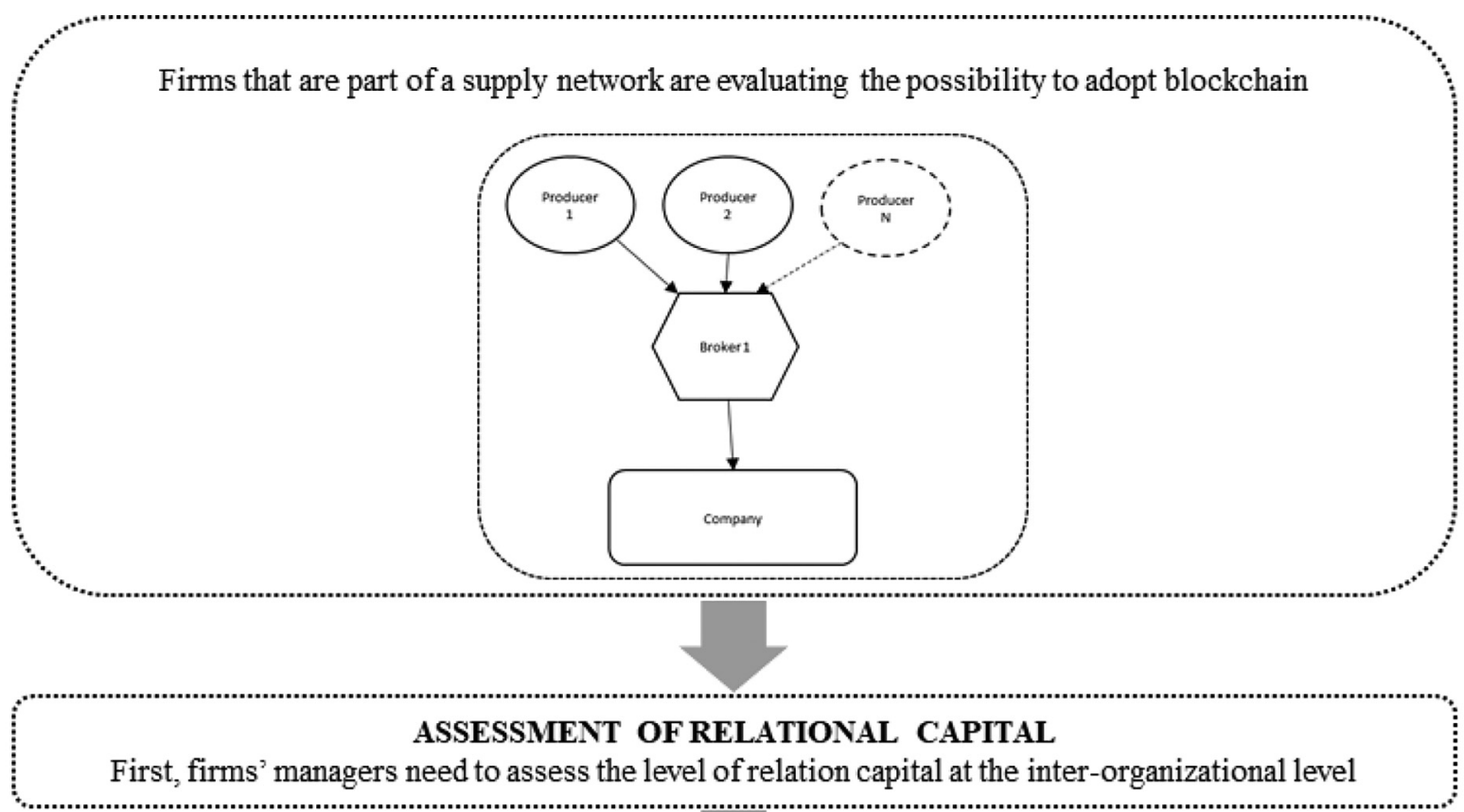

First, firms' managers need to assess the level of relation capital at the inter-organizational level

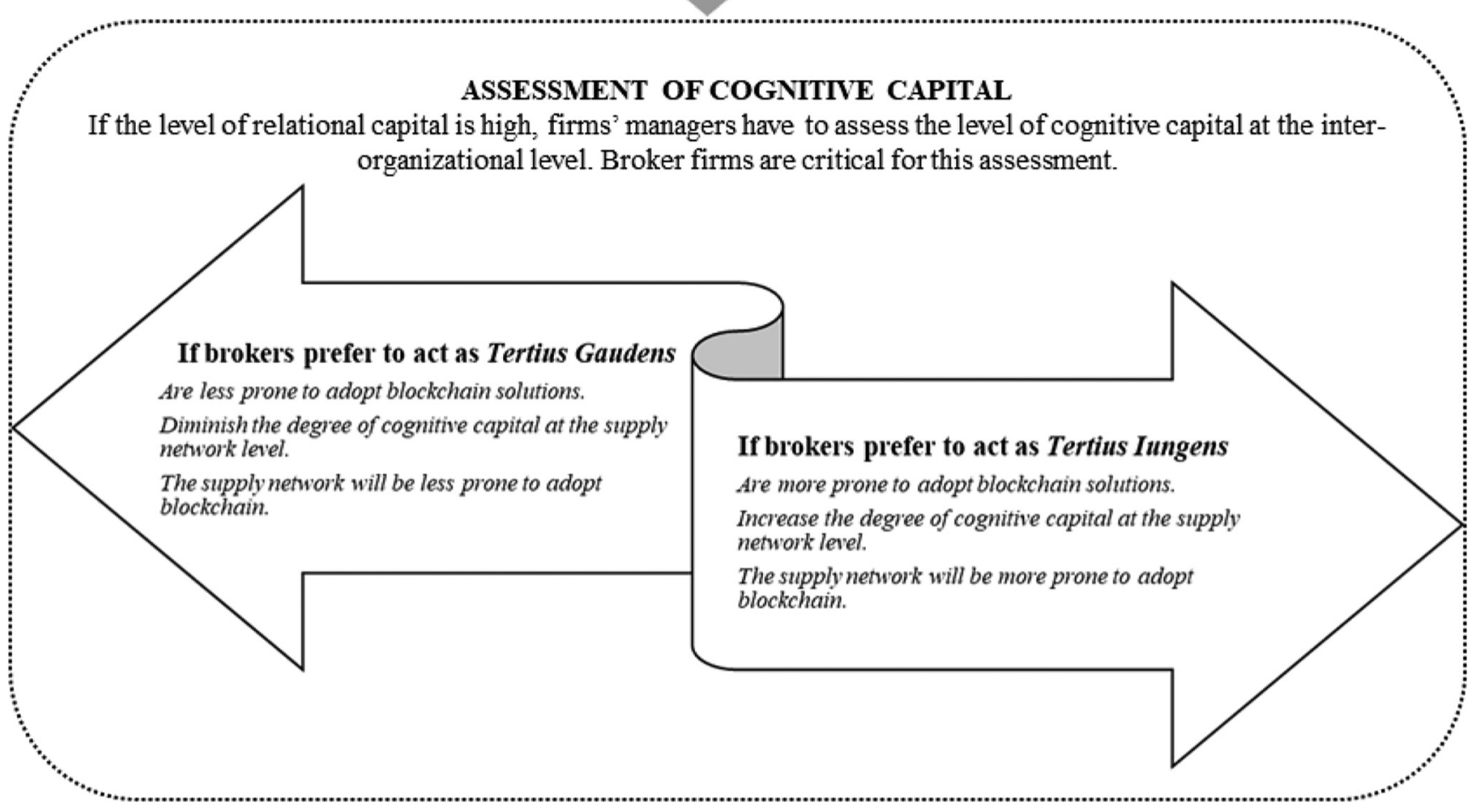

relational embeddedness achieved with partners. In particular, our study reveals that firms' managers that want to adopt blockchain within their supply chain need to undertake a thorough and exhaustive assessment of relational capital and cognitive capital at the inter-organizational level, in addition to the structural dimension that was investigated and confirmed as relevant in previous studies.
Managers need to understand why and with whom they wish to start this process. In the pre-adoption stage, each firm's managers need to evaluate not only the benefits and drawbacks arising from blockchain implementation when considering their own perspective but need to reflect also the partners. This must be done by considering the level of relational capital at the supply network level, which means an assessment of partners' 
trustworthiness, the presence of strong or weak bonds between buyers and suppliers (by evaluating, for example, the frequency of joint problem-solving, the presence of obligations or the distance maintained between them) and the existence of shared norms between firms. As stressed in this study, this can be considered a necessary condition to start a blockchain implementation journey.

However, that's not all. After evaluating relational issues, each firm's managers need also to assess the competitive position and the strategic outlook of the other partners, those who are evaluating the blockchain adoption process. More in detail, our study identifies brokers as crucial firms to be assessed in these terms. Therefore, each firm should deepen the understanding of traders' and brokers' competitive and strategic thinking. Brokers' decision (to preserve or not their competitive advantage by hindering information flows and connections between unconnected firms in the network) affects the adoption or not of blockchain. Other firms' managers, by being aware of brokers' strategic outlook, can decide to abandon blockchain implementation or to try to influence broker managers' perspectives, according to the importance given to the adoption of blockchain at the network level.

Finally, our findings highlight an implication also for brokers' managers. Following the findings that emerged from Case 1, the decision to adopt blockchain may lead the broker's customers to believe that the broker firm is trustworthy, more than other brokers, thus leading to an increase in the broker's incomes. This because the implementation of blockchain can be considered a signal of trustworthiness. Thus, although blockchain implementation should reduce brokers' bargaining power, it can also produce a positive effect on broker's profit.

\subsection{Limitations and future research}

The study is affected by some limitations. First, given the research design, the results have limited generalizability. The study refers to one industry, the food one, which has its idiosyncrasies. In addition, the low number of case studies is another limitation. However, we believe that, given the structure of the chain investigated as well as the rationale of the interviewed firms' managers, our study could be considered helpful also for managers belonging to other industries and for scholars investigating blockchain in different contexts. Second, the study is subjected to retrospective bias, given that interviews collected managers' viewpoints referred to decisions made in the past. Third, it was claimed that relational capital can be considered a necessary condition to adopt blockchain. Although this result derives from both the cases investigated, there is a need to go further with the understanding of this issue.

As for future research, in addition to studies aimed at confirming or denying the validity of findings, two future research paths, which could help to advance the understanding of the topic more than others, are suggested. A first interesting avenue for research is represented by a more profound understanding of the effects of competitive considerations on cognitive capital in the pre-adoption stage. While this study suggests that divergences in terms of shared goals at the supply network level are attributable to brokering opportunities, future research could explore more complex arrangements by leveraging, for example, on the co-opetitive dynamics in supply chain archetypes proposed by Pathak et al. (2014).

Second, it could be also of interest to investigate network closure implications by relying on social network theory or on additional theoretical perspectives with reference to the postadoption stage. Future research could start by considering that the closure of a structural hole prompts a network-wide reaction, as stressed by Pathak et al. (2014). Blockchain could potentially fill several structural holes in the supply network, thereby triggering several adaptive behaviors at the network level, which, in turn, could have implications on social capital and on competitive dynamics at the supply chain level.

\section{References}

Allen, D.W., Berg, C., Markey-Towler, B., Novak, M. and Potts, J. (2020), "Blockchain and the evolution of institutional technologies: implications for innovation policy”, Research Policy, Vol. 49 No. 1, p. 103865.

Baker, W.E. and Obstfeld, D. (1999), "Social capital by design: structures, strategies, and institutional context", Corporate Social Capital and Liability, Springer, pp. 88-105.

Barney, J. (1991), "Special theory forum the resource-based model of the firm: origins, implications, and prospects", Fournal of Management, Vol. 17 No. 1, pp. 97-98.

Bernardes, E.S. (2010), "The effect of supply management on aspects of social capital and the impact on performance: a social network perspective", fournal of Supply Chain Management, Vol. 46 No. 1, pp. 45-55.

Birkel, H.S. and Hartmann, E. (2019), "Impact of IoT challenges and risks for SCM", Supply Chain Management: An International fournal, Vol. 24 No. 1, pp. 39-61.

Birkel, H.S. and Hartmann, E. (2020), "Internet of things-the future of managing supply chain risks", Supply Chain Management: An International fournal, Vol. 25 No. 5,

Bourdieu, P. (1986), "The forms of capital", in Richardson, J. G. (Ed.), Handbook of Theory and Research for the Sociology of Education, Greenwood, New York, NY, pp. 241-258.

Brinch, M., Stentoft, J. and Näslund, D. (2020), “Alignment capabilities of big data's value creation in the context of service delivery processes", Supply Chain Management: An International fournal.

Burt, R.S. (2001), "Structural holes versus network closure as social capital", in Lin, N., Cook, K.S. and Burt, R.S. (Eds), Social Capital: Theory and Research, Aldine de Gruyter, New York, NY, pp. 31-56.

Burt, R.S. (2007), "Secondhand brokerage: evidence on the importance of local structure for managers, bankers, and analysts", Academy of Management Fournal, Vol. 50 No. 1, pp. 119-148.

Burt, R.S. (2009), Structural Holes: The Social Structure of Competition, Harvard University Press, Boston, MA.

Calatayud, A., Mangan, J. and Christopher, M. (2019), "The self-thinking supply chain”, Supply Chain Management: An International fournal, Vol. 24 No. 1, pp. 22-38.

Carnovale, S., Rogers, D.S. and Yeniyurt, S. (2016), "Bridging structural holes in global manufacturing equity based partnerships: a network analysis of domestic vs. international joint venture formations", fournal of Purchasing and Supply Management, Vol. 22 No. 1, pp. 7-17. 
Choi, T.Y., Dooley, K.J. and Rungtusanatham, M. (2001), "Supply networks and complex adaptive systems: control versus emergence", fournal of Operations Management, Vol. 19 No. 3, pp. 351-366.

Cole, R., Stevenson, M. and Aitken, J. (2019), "Blockchain technology: implications for operations and supply chain management", Supply Chain Management: An International Fournal, Vol. 24 No. 4, pp. 469-483.

Cong, L.W. and He, Z. (2019), "Blockchain disruption and smart contracts", The Review of Financial Studies, Vol. 32 No. 5, pp. 1754-1797.

Cousins, P.D., Lawson, B. and Squire, B. (2006), "Supply chain management: theory and practice-the emergence of an academic discipline?", International fournal of Operations $\mathcal{E}$ Production Management, Vol. 26 No. 7, pp. 697-702.

Davidson, S., De Filippi, P. and Potts, J. (2018), "Blockchains and the economic institutions of capitalism", fournal of Institutional Economics, Vol. 14 No. 4, pp. 639-658.

Dolci, P.C., Maçada, A.C.G. and Paiva, E.L. (2017), "Models for understanding the influence of supply chain governance on supply chain performance", Supply Chain Management: An International fournal, Vol. 22 No. 5, pp. 424-441.

Dyer, J.H. (1997), "Effective interim collaboration: how firms minimize transaction costs and maximise transaction value", Strategic Management fournal, Vol. 18 No. 7, pp. 535-556.

Frederico, G.F., Garza-Reyes, J.A., Anosike, A. and Kumar, V. (2019), "Supply chain 4.0: concepts, maturity and research agenda", Supply Chain Management: An International fournal, Vol. 25 No. 2.

Gaggioli, A. (2018), "Blockchain technology: living in a decentralized everything", Cyberpsychology, Behavior, and Social Networking, Vol. 21 No. 1, pp. 65-66.

Galati, F. and Bigliardi, B. (2019a), "Industry 4.0: emerging themes and future research avenues using a text mining approach", Computers in Industry, Vol. 109, pp. 100-113.

Galati, F. and Bigliardi, B. (2019b), "Redesigning the model of the initiation and evolution of inter-firm knowledge transfer in R\&D relationships", Fournal of Knowledge Management, Vol. 23 No. 10.

Galati, F., Bigliardi, B., Galati, R. and Petroni, G. (2019), "Managing structural inter-organizational tensions in complex product systems projects: lessons from the metis case", Fournal of Business Research, in press.

Garcia-Torres, S., Albareda, L., Rey-Garcia, M. and Seuring, S. (2019), "Traceability for sustainability-literature review and conceptual framework", Supply Chain Management: An International fournal, Vol. 24 No. 1, pp. 85-106.

Ghosh, A. and Fedorowicz, J. (2008), "The role of trust in supply chain governance", Business Process Management Fournal, Vol. 14 No. 4, pp. 453-470.

Gligor, D., Bozkurt, S., Russo, I. and Omar, A. (2019), “A look into the past and future: theories within supply chain management, marketing and management", Supply Chain Management: An International fournal, Vol. 24 No. 1, pp. 170-186.

Granovetter, M. (1992), "Economic institutions as social constructions: a framework for analysis", Acta Sociologica, Vol. 35 No. 1, pp. 3-11.

Gulati, R. (1998), “Alliances and networks", Strategic Management foumal, Vol. 19 No. 4, pp. 293-317.
Gupta, S.S. (2017), Blockchain, John Wiley \& Sons, Hoboken, NJ.

Hald, K.S. and Kinra, A. (2019), "How the blockchain enables and constrains supply chain performance", International Fournal of Physical Distribution \& Logistics Management, Vol. 49 No. 4, pp. 376-397.

Halldorsson, A., Kotzab, H., Mikkola, J.H. and Skjøtt-Larsen, T. (2007), "Complementary theories to supply chain management", Supply Chain Management: An International fournal, Vol. 12 No. 4, pp. 284-296.

Iansiti, M. and Lakhani, K.R. (2017), "The truth about blockchain”, Harvard Business Review, Vol. 95 No. 1, pp. 118-127.

Ihlen, Ø. (2005), "The power of social capital: adapting Bourdieu to the study of public relations", Public Relations Review, Vol. 31 No. 4, pp. 492-496.

Inkpen, A.C. and Tsang, E.W. (2005), "Social capital, networks, and knowledge transfer", Academy of Management Review, Vol. 30 No. 1, pp. 146-165.

Jensen, M.C. and Meckling, W.H. (1976), “Theory of the firm: managerial behavior, agency costs and ownership structure", Fournal of Financial Economics, Vol. 3 No. 4, pp. 305-360.

Johnson, N., Elliott, D. and Drake, P. (2013), "Exploring the role of social capital in facilitating supply chain resilience", Supply Chain Management: An International fournal, Vol. 18 No. 3, pp. 324-336.

Kim, J.S. and Shin, N. (2019), "The impact of blockchain technology application on supply chain partnership and performance", Sustainability, Vol. 11 No. 21, pp. 6181

Krause, D.R., Handfield, R.B. and Tyler, B.B. (2007), "The relationships between supplier development, commitment, social capital accumulation and performance improvement", Fournal of Operations Management, Vol. 25 No. 2, pp. 528-545.

Kumar, A., Liu, R. and Shan, Z. (2019), "Is blockchain a silver bullet for supply chain management? Technical challenges and research opportunities", Decision Sciences, Vol. 51 No. 1.

Lamming, R., Johnsen, T., Zheng, J. and Harland, C. (2000), "An initial classification of supply networks", International Fournal of Operations $\mathcal{E}$ Production Management, Vol. 20 No. 6, pp. 675-691.

Liboni, L.B., Cezarino, L.O., Jabbour, C.J.C., Oliveira, B.G. and Stefanelli, N.O. (2019), "Smart industry and the pathways to HRM 4.0: implications for SCM", Supply Chain Management: An International fournal, Vol. 24 No. 1, pp. 124-146.

Lin, N. (2002), Social Capital: A Theory of Social Structure and Action, Cambridge University Press, Cambridge.

Long Lingo, E. and O’Mahony, S. (2010), "Nexus work: brokerage on creative projects", Administrative Science Quarterly, Vol. 55 No. 1, pp. 47-81.

Mora-Monge, C., Quesada, G., Gonzalez, M.E. and Davis, J. M. (2019), "Trust, power and supply chain integration in web-enabled supply chains", Supply Chain Management: An International fournal, Vol. 24 No. 4.

Nahapiet, J. and Ghoshal, S. (1998), "Social capital, intellectual capital, and the organizational advantage", Academy of Management Review, Vol. 23 No. 2, pp. 242-266.

Nandi, M.L., Nandi, S., Moya, H. and Kaynak, H. (2020), "Blockchain technology-enabled supply chain systems and 
supply chain performance: a resource-based view", Supply Chain Management: An International fournal, Vol. 25 No. 6.

Obstfeld, D. (2005), "Social networks, the tertius iungens orientation, and involvement in innovation", Administrative Science Quarterly, Vol. 50 No. 1, pp. 100-130.

Obstfeld, D., Borgatti, S.P. and Davis, J. (2014), "Brokerage as a process: decoupling third party action from social network structure", Contemporary Perspectives on Organizational Social Networks, Emerald Group Publishing, pp. 135-159.

Pasi, B.N., Mahajan, S.K. and Rane, S.B. (2020), "Smart supply chain management: a perspective of industry 4.0 ", Supply Chain Management, Vol. 29 No. 5, pp. 3016-3030.

Pathak, S.D., Wu, Z. and Johnston, D. (2014), "Toward a structural view of co-opetition in supply networks", fournal of Operations Management, Vol. 32 No. 5, pp. 254-267.

Pfeffer, J. and Salancik, G.R. (1978), The External Control of Organizations: A Resource Dependence Perspective, Harper \& Row, New York, NY.

Polanyi, M. (1962), "Tacit knowing: its bearing on some problems of philosophy", Reviews of Modern Physics, Vol. 34 No. 4, p. 601 .

Queiroz, M.M. and Wamba, S.F. (2019), "Blockchain adoption challenges in supply chain: an empirical investigation of the main drivers in India and the USA", International fournal of Information Management, Vol. 46, pp. 70-82.

Queiroz, M.M., Telles, R. and Bonilla, S.H. (2019), "Blockchain and supply chain management integration: a systematic review of the literature", Supply Chain Management: An International fournal, Vol. 25 No. 2.

Quintane, E. and Carnabuci, G. (2016), "How do brokers broker? Tertius gaudens, tertius iungens, and the temporality of structural holes", Organization Science, Vol. 27 No. 6, pp. 1343-1360.

Quintas, P., Lefrere, P. and Jones, G. (1997), "Knowledge management: a strategic agenda", Long Range Planning, Vol. 30 No. 3, pp. 385-391.

Rogerson, M. and Parry, G.C. (2020), "Blockchain: case studies in food supply chain visibility", Supply Chain Management: An International fournal, Vol. 25 No. 5.

Schmidt, C.G. and Wagner, S.M. (2019), "Blockchain and supply chain relations: a transaction cost theory perspective", fournal of Purchasing and Supply Management, Vol. 25 No. 4, p. 100552 .

Scholten, K., Scott, P.S. and Fynes, B. (2019), "Building routines for non-routine events: supply chain resilience learning mechanisms and their antecedents", Supply Chain Management: An International fournal, Vol. 24 No. 3, pp. 430-442.

Seepma, A.P., de Blok, C. and Van Donk, D.P. (2020), "Designing digital public service supply chains: four countrybased cases in criminal justice", Supply Chain Management: An International fournal.

Strauss, A.L. and Corbin, J. (1998), Basics of Qualitative Research, Sage, Thousand Oaks, CA.

Swierczek, A. (2020), "Relational orientation of triadic supply chains with structural holes: an empirical comparison of rents derived from bridging the structural holes", Supply Chain Management: An International fournal, Vol. 25 No. 5.
Timmermans, S. and Tavory, I. (2012), "Theory construction in qualitative research: from grounded theory to abductive analysis", Sociological Theory, Vol. 30 No. 3, pp. 167-186.

Treiblmaier, H. (2018), "The impact of the blockchain on the supply chain: a theory-based research framework and a call for action", Supply Chain Management: An International fournal, Vol. 23 No. 6, pp. 545-559.

van Veen-Dirks, P.M. and Verdaasdonk, P.J. (2009), "The dynamic relation between management control and governance structure in a supply chain context", Supply Chain Management: An International fournal, Vol. 14 No. 6, pp. 466-478.

Wang, Y., Singgih, M., Wang, J. and Rit, M. (2019), "Making sense of blockchain technology: how will it transform supply chains?", International fournal of Production Economics, Vol. 211, pp. 221-236.

Williamson, O.E. (1999), "Strategy research: governance and competence perspectives", Strategic Management fournal, Vol. 20 No. 12, pp. 1087-1108.

Woolcock, M. (1998), "Social capital and economic development: toward a theoretical synthesis and policy framework", Theory and Society, Vol. 27 No. 2, pp. 151-208.

Wu, W. (2008), "Dimensions of social capital and firm competitiveness improvement: the mediating role of information sharing", fournal of Management Studies, Vol. 45 No. 1, pp. 122-146.

Wu, Z. and Choi, T.Y. (2005), "Supplier-supplier relationships in the buyer-supplier triad: building theories from eight case studies", fournal of Operations Management, Vol. 24 No. 1, pp. 27-52.

Yin, R.K. (2009), Case Study Research: Design and Methods, Essential Guide to Qualitative Methods in Organizational Research, Sage Publications, London, Vol.5.

Yli-Huumo, J., Ko, D., Choi, S., Park, S. and Smolander, K. (2016), "Where is current research on blockchain technology? - A systematic review", PloS One, Vol. 11 No. 10, p. e0163477.

Zacharia, Z.G., Nix, N.W. and Lusch, R.F. (2009), "An analysis of supply chain collaborations and their effect on performance outcomes", fournal of Business Logistics, Vol. 30 No. 2, pp. 101-123.

\section{Further reading}

Doz, Y.L. (1996), "The evolution of cooperation in strategic alliances: initial conditions or learning processes?", Strategic Management fournal, Vol. 17, pp. 55-83.

Dyer, J.H. and Singh, H. (1998), "The relational view: cooperative strategy and sources of interorganizational competitive advantage", Academy of Management Review, Vol. 23 No. 4, pp. 660-679.

Gulati, R., Nohria, N. and Zaheer, A. (2000), "Strategic networks", Strategic Management Fournal, Vol. 21 No. 3, pp. 203-215.

Gulbrandsen, B., Sandvik, K. and Haugland, S.A. (2009), "Antecedents of vertical integration: transaction cost economics and resource-based explanations", fournal of Purchasing and Supply Management, Vol. 15 No. 2, pp. 89-102. 
Heide, J.B. and John, G. (1990), “Alliances in industrial purchasing: the determinants of joint action in buyersupplier relationships", fournal of Marketing Research, Vol. 27 No. 1, pp. 24-36.

Miles, M.B. and Huberman, M.A. (1994), Qualitative Data Analysis: An Expanded Sourcebook, Sage, Thousand Oaks, CA.

Nelson, R.R. and Winter, S.G. (1982), "The Schumpeterian tradeoff revisited", The American Economic Review, Vol. 72 No. 1, pp. 114-132.

Reuer, J.J., Zollo, M. and Singh, H. (2002), "Post-formation dynamics in strategic alliances", Strategic Management fournal, Vol. 23 No. 2, pp. 135-151.

Subramani, M.R. and Venkatraman, N. (2003), "Safeguarding investments in asymmetric interorganizational relationships: theory and evidence", Academy of Management fournal, Vol. 46 No. 1, pp. 46-62.

Teece, D.J. (1986), "Profiting from technological innovation: implications for integration, collaboration, licensing and public policy", Research Policy, Vol. 15 No. 6, pp. 285-305. van Hoek, R. (2019), "Unblocking the chain-findings from an executive workshop on blockchain in the supply chain", Supply Chain Management: An International fournal, Vol. 25 No. 2.

\section{About the author}

Francesco Galati graduated (with distinction) in 2009 in Industrial Engineering and Management at the University of Parma and received his $\mathrm{PhD}$ in Industrial Engineering from the same University. $\mathrm{He}$ is a researcher at the University of Parma. His research activities mainly concern knowledge asset and intellectual capital management, innovation and interorganizational relationships. He has authored or co-authored more than 60 papers published in an international journal, as well as on national and international conference proceedings. $\mathrm{He}$ acts as a referee for more than 30 international scientific journals. Francesco Galati can be contacted at: francesco. galati@unipr.it 